\title{
Article \\ Hand Hygiene Evaluation Using Two Different Evaluation Tools and Hand Contamination of Veterinary Healthcare Workers in a Swiss Companion Animal Clinic
}

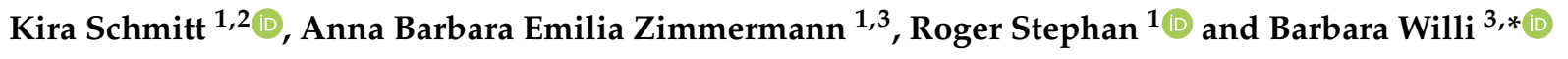 \\ 1 Section of Veterinary Bacteriology, Institute for Food Safety and Hygiene, University of Zurich, \\ Winterthurerstrasse 272, CH-8057 Zurich, Switzerland; kira.schmitt@uzh.ch (K.S.); \\ annabarbaraemilia.zimmermann@uzh.ch (A.B.E.Z.); roger.stephan@uzh.ch (R.S.) \\ 2 Graduate School for Cellular and Biomedical Sciences, University of Bern, Mittelstrasse 43, \\ CH-3012 Bern, Switzerland \\ 3 Clinic for Small Animal Internal Medicine, University of Zurich, Winterthurerstrasse 260, \\ CH-8057 Zurich, Switzerland \\ * Correspondence: bwilli@vetclinics.uzh.ch
}

check for updates

Citation: Schmitt, K.; Zimmermann, A.B.E.; Stephan, R.; Willi, B. Hand Hygiene Evaluation Using Two Different Evaluation Tools and Hand Contamination of Veterinary Healthcare Workers in a Swiss Companion Animal Clinic. Vet. Sci. 2021, 8, 260. https://doi.org/ $10.3390 /$ vetsci 8110260

Academic Editor: Kristina Kadlec

Received: 28 June 2021

Accepted: 29 October 2021

Published: 2 November 2021

Publisher's Note: MDPI stays neutral with regard to jurisdictional claims in published maps and institutional affiliations.

Copyright: (C) 2021 by the authors. Licensee MDPI, Basel, Switzerland. This article is an open access article distributed under the terms and conditions of the Creative Commons Attribution (CC BY) license (https:/ / creativecommons.org/licenses/by/ $4.0 /)$.

\begin{abstract}
Hand hygiene $(\mathrm{HH})$ is the most important measure to prevent nosocomial infections. $\mathrm{HH}$ compliance in companion animal clinics has been reported to be poor. The present study compared an online application with the WHO evaluation form to assess the WHO five moments of $\mathrm{HH}$ in a Swiss companion animal clinic. In 202 hand swabs from 87 staff members, total viable count (TVC) before and after patient contact was evaluated and the swabs were tested for selected antimicrobial resistant microorganisms of public health importance. HH compliance ( $95 \%$ confidence interval) was $36.6 \%$ (33.8-39.5\%) and was similar when assessed with the two evaluation tools. HH differed between hospital areas $(p=0.0035)$ and $\mathrm{HH}$ indications $(p<0.0001)$. Gloves were worn in $22.0 \%(18.0-26.6 \%)$ of $\mathrm{HH}$ observations and were indicated in $37.2 \%(27.3-48.3 \%)$ of these observations. Mean TVC before patient contact was lower $\left(0.52 \log \mathrm{CFU} / \mathrm{cm}^{2}\right)$ than after patient contact $\left(1.02 \log \mathrm{CFU} / \mathrm{cm}^{2}\right)$ but was similar before patient contact on gloved and ungloved hands. Three hand swabs $(1.5 \%(0.4-4.3 \%))$ were positive for methicillin-resistant Staphylococcus aureus. Gloving should not be regarded as a substitute for $\mathrm{HH}$. Overall, $\mathrm{HH}$ in companion animal medicine should urgently be fostered.
\end{abstract}

Keywords: hand; hygiene; infection prevention control; hospital; antibiotic resistance

\section{Introduction}

Hand hygiene $(\mathrm{HH})$ in companion animal clinics is of particular importance as intensive medical care of dogs and cats can be associated with nosocomial infections. $\mathrm{HH}$ is particularly crucial for geriatric and immunosuppressed animal patients which are more susceptible to infections and subsequent severe negative health outcomes [1-4]. Companion animals often receive antimicrobial therapy, including high priority critically important antimicrobials and last resort antibiotics, such as carbapenems [5-16]. Infection prevention and control standards in the companion animal healthcare sector are often insufficient and can contribute to the distribution of antimicrobial resistant microorganisms (ARM) between the environment and healthcare personnel [17]. Additionally, the close contact between owners and their pets poses the risk of transmission of ARM, such as extended-spectrum beta-lactamase-producing Enterobacteriaceae (ESBL-E) [18-21].

$\mathrm{HH}$ is the most important prevention measure against nosocomial infections in human medicine [22-24]. Approximately 30\% of hospital-acquired infections are considered preventable [25]. Healthcare workers' hands are one of the main risk factors for transmission of microorganisms between patients and the environment [26]. In a recent systematic review, average baseline $\mathrm{HH}$ compliance among healthcare workers in human adult intensive care units was reported to be $51.5 \%$, increasing to $80.1 \%$ after intervention [27]. 
The WHO defines five indications (moments) in which HH should be carried out. They represent those situations which carry the highest risk for contamination of medical personnel's hands inadvertently leading to transmission of pathogens $[26,28]$. Direct observation of staff during patient care by trained and validated observers using online tools or observation forms is considered the gold standard for monitoring hand hygiene [26]. $\mathrm{HH}$ is defined as the use of hand disinfection with an alcohol-based disinfectant or the washing of hands with soap and water. Alcohol-based hand disinfectant should contain $60-95 \%$ ethanol or isopropyl alcohol [29]. When indicated, for example, when hands are visibly soiled or dirty, hands should be washed with a nonmedicated soap. For optimal compliance, hand hygiene products should be readily available [30]. The use of gloves is disregarded as $\mathrm{HH}$ and has frequently been discussed as a barrier to $\mathrm{HH}$, since gloves do not provide complete protection against hand contamination. Pathogens can be transferred onto the hands through small defects in the gloves or through contamination of the hands during glove removal. The WHO recommends the use of gloves to be limited to contact with potentially infectious material or patients, expected body fluid exposure risk, for clean/aseptic/invasive procedures and for cleaning and disinfection. They should only be worn for as long as necessary and contact with "clean" surfaces should be avoided [26,30]. $\mathrm{HH}$ should also be practiced before putting on gloves and after glove removal in accordance with the WHO five moments of $\mathrm{HH}$, independent of glove usage.

$\mathrm{HH}$ compliance in companion animal medicine has been assessed in few studies. Compliance ranged from $14 \%$ to $27 \%$ before intervention, and up to $14 \%$ to $42 \%$ after intervention [31-33]. These results are in line with a recent study from Switzerland, which evaluated $\mathrm{HH}$ compliance in seven companion animal clinics and practices. Adherence of employees to the WHO five moments of $\mathrm{HH}$ was insufficient in all institutions and ranged from $26 \%$ to $47 \%$ [34]. HH compliance did not differ between large and medium-sized clinics or between the three large clinics included in the study. However, $\mathrm{HH}$ compliance was significantly different between the five $\mathrm{HH}$ indications and between the clinical areas in the large clinics [34].

Overall, data regarding $\mathrm{HH}$ compliance in companion animal medicine, especially regarding the use of gloves and the type of HH carried out, is limited. Furthermore, no data is available on hand swabs in conjunction with $\mathrm{HH}$ evaluation. The goal of this study was to assess the $\mathrm{WHO}$ five moments for $\mathrm{HH}$, the type of $\mathrm{HH}$ being implemented, and the use of gloves in a tertiary care facility in Switzerland, using the online application CleanHands (Swissnoso, National Centre for Infection Prevention, Bern, Switzerland) and the WHO evaluation form [35]. Additionally, the present study investigated hand swabs of companion animal healthcare workers for contamination with ESBL-E, carbapenemaseproducing Enterobacteriaceae (CPE), vancomycin-resistant enterococci (VRE), methicillinresistant Staphylococcus aureus (MRSA), and Staphylococcus pseudintermedius (MRSP). Hand contamination was evaluated in relation to $\mathrm{HH}$ procedures in different clinical areas in the care facility.

\section{Materials and Methods}

This study was conducted at a large tertiary referral hospital for small animals, covering a wide range of specialty services, with approximately 200 employees and 10,000 patients per year offering a $24-\mathrm{h}, 365$ days a year emergency service including an intensive care unit (ICU). At the beginning of the study, an information sheet was distributed by the clinic's communication platform to announce the study to the clinical staff. The clinic used the same alcohol-based hand disinfectant (Desmanol ${ }^{\circledR}$ pure, $75 \%$ Propan-2-ol, Schülke \& Mayr AG, Zurich, Switzerland) and soap (S\&M ${ }^{\circledR}$ wash lotion, Schülke \& Mayr AG, Zürich, Switzerland) in all clinical areas and the products remained unchanged throughout the study period. 


\subsection{Hand Hygiene Evaluation}

$\mathrm{HH}$ compliance was evaluated according to the WHO five moments of $\mathrm{HH}$ (after body fluid exposure risk, after patient contact, after touching the patient's surroundings, before clean/aseptic/invasive procedures, and before patient contact; Table S1) as previously described [34], using the CleanHands application (Swissnoso, National Centre for Infection Prevention) [36] as well as the WHO evaluation form [35]. Both tools were used to equally evaluate $\mathrm{HH}$ (i.e., carried out or not) in five different clinical areas: consultation rooms, wards, examination area for hospitalized patients, intensive-care unit (ICU) and pre-operation preparation area. Additionally, $\mathrm{HH}$ compliance across professional groups (veterinarians; nurses and others, i.e., personnel not allocated to the aforementioned categories, such as students and technicians) was analyzed. All observations were carried out by the same observer over a period of ten weeks. The observer had been previously trained by an experienced observer [34]. For ethical reasons, and in accordance with the WHO recommendations, the observer introduced herself and stated the reason for her presence before the start of each session without going into more detail about the indications or $\mathrm{HH}$ activities [30]. The observer then positioned herself inconspicuously and started the session. To minimize selection bias, each session was started in a randomly selected clinical area. After 30 min of observation, the evaluation was continued in the following order in another area: ICU, wards, consultation rooms, examination area for hospitalized patients, and finally the pre-operation preparation area. If there was no activity in a particular area for more than five minutes, the evaluation was continued in a different area. The first person to be encountered in the respective clinical area was observed during an entire activity. Another randomly selected person was observed thereafter. No more than three people were observed at once $[36,37]$ and a maximum of two activities per session were observed per healthcare worker. If more than one indication of hand hygiene was given, the following prioritization was applied: before clean/aseptic/invasive procedure, after body fluid exposure risk, after patient contact, before patient contact, and after touching the patient's surroundings. The prioritization is based on a local consensus, weighing the perceived risk of infection for the patient against the risk of microbiological contamination of the healthcare workers' hands. The prioritization scheme has been used in previous studies in human and veterinary medicine [26,34]. In contrast to the CleanHands application available at the time of this study, the WHO evaluation form additionally allows recording of the type of $\mathrm{HH}$ that was practiced (hand disinfection with alcohol-based hand rub or hand washing with water and soap) and documenting the use of gloves and whether $\mathrm{HH}$ was carried out according to WHO criteria when using gloves. Glove usage was categorized as appropriate according to $\mathrm{WHO}$ guidelines when activities involved expected body fluid exposure risk and when clean/aseptic/invasive procedures were performed. $\mathrm{HH}$ and the use of gloves was not evaluated during contact precautions when treating infectious patients, as the clinic had defined specific hygiene measures for these instances. After digital recording of the observations with the CleanHands application, the data was extracted from the software as Excel files for further statistical analyses. The data obtained with the WHO evaluation tool was manually transferred to Excel files for statistical analyses.

\subsection{Hand Swabs Collection}

Hand swabs of the entire dominant hand palm, fingers and thumb were collected before and after patient contact using a sterile cotton swab moisturized with $0.85 \%$ saline solution. Hand swabs were processed immediately after sample collection. If gloves were worn, hand swabs were taken from the gloved hand before and after patient contact. The same type of gloves (Sempercare ${ }^{\circledR}$ velvet, non-sterile, powder-free single use nitrile examination and protective gloves, IVF Hartmann AG, Neuhausen, Switzerland) were available in all areas of the clinic and remained the same throughout the study period. To reduce potential observer bias, hand swabs were taken during busy daily procedures and in areas with a high density of patients and personnel (wards, 62 samples; examination 
area, 66 samples; ICU, 74 samples, respectively). The healthcare workers were approached immediately before animal contact without any prior announcement. A coded sample collection procedure was used and hence no personal data was collected from the study participants to ensure that employers did not feel obliged to change their individual hand hygiene behavior. The hand swab collection and the aforementioned hand hygiene observations were conducted in a mutually exclusive fashion. For data interpretation purposes, the hand hygiene procedure carried out before and after hand swab collection was noted. All study participants gave written informed consent. This study was approved by the Swiss Ethics Committee on research involving humans (approval No. 2019-00768).

\subsection{Microbiological Analysis}

Hand swabs were homogenized for $60 \mathrm{~s}$ in $10 \mathrm{~mL}$ peptone water (BioRad, Hercules, CA, USA) using a Stomacher ${ }^{\circledR} 400$ (Seward, Worthing, UK). Afterwards, $1 \mathrm{~mL}$ was used to prepare decimal dilution series $(0.85 \%$ saline solution). Aliquots of $0.1 \mathrm{~mL}$ were then transferred to plate count agar (BioRad, Hercules, CA, USA) and distributed by applying the spreading method. Total viable counts (TVC) were calculated as CFU/ $\mathrm{cm}^{2}$ after incubation for $72 \mathrm{~h}$ at $30{ }^{\circ} \mathrm{C}$. TVC were expressed as $\log \mathrm{CFU} / \mathrm{cm}^{2}$. The definitions for hand surface area and the calculation methods vary across the literature and depend on the investigated population. The size of the hand was determined as $100 \mathrm{~cm}^{2}$ for the purpose of this study $[38,39]$. The detection limit was $1 \mathrm{CFU} / \mathrm{cm}^{2}$. A log value of zero was used for counts below the detection limit.

The remaining homogenate of each hand swab sample was enriched $\left(37^{\circ} \mathrm{C}, 24 \mathrm{~h}\right)$, followed by selective enrichment for ESBL-E and CPE in Enterobacteriaceae enrichment broth (Oxoid, Hampshire, UK), in BHI (BioRad, Hercules, CA, USA) with 6.5\% saline solution for VRE, and additionally in Mueller Hinton broth (Oxoid, Hampshire, UK) with 6.5\% saline solution followed by an enrichment in tryptone soy broth (Becton Dickinson, Allschwil, Switzerland) with $4 \mathrm{mg} / \mathrm{L}$ cefoxitin and $75 \mathrm{mg} / \mathrm{L}$ aztreonam for the detection of MRSA and MRSP. ESBL-E were screened using chromogenic medium Brilliance ${ }^{\mathrm{TM}}$ ESBL Agar (Oxoid, Hampshire, UK), CPE by using chromID ${ }^{\circledR}$ CARBA SMART Bi-Plate-Agar (bioMérieux, Marcy-l'Étoile, France), VRE by using Brilliance ${ }^{\mathrm{TM}}$ VRE Agar (Oxoid, Hampshire, UK) and MRSA and MRSP by using Brilliance ${ }^{\mathrm{TM}}$ MRSA2 Agar (Oxoid, Hampshire, UK), according to the manufacturer's instructions. Species identification was conducted by using a matrixassisted laser desorption/ionization time-of-flight mass spectrometry (MALDI-TOF-MS, Bruker Daltronics, Bremen, Germany).

Polymerase chain reaction (PCR) was carried out to screen for the presence of genes encoding $b l a_{\mathrm{CTX}-\mathrm{M}}$ group enzymes, $b l a_{\mathrm{SHV}}$ and $b l a_{\mathrm{TEM}}$ as previously described [40-43]. PCR targeting $b l a_{\mathrm{VIM}}, b l a_{\mathrm{KPC}}, b l a_{\mathrm{OXA}-48}-$ like and $b l a_{\mathrm{NDM}}$ genes was carried out using custom synthesized primers (Microsynth, Balgach, Switzerland) and conditions published previously [44,45]. Multiplex PCR for the presence of $\operatorname{van} A$, vanB and $\operatorname{van} C_{1,2,3}$ was conducted as previously described using custom synthesized primers (Microsynth, Balgach, Switzerland) [46]. PCR for the presence of mecA and mecC was conducted using custom synthesized primers (Microsynth, Balgach, Switzerland) as previously described [47,48].

\subsection{Statistical Analysis}

For statistical analysis, commercially available GraphPad PRISM ${ }^{\circledR}$ software (San Diego, CA, USA) was used. Descriptive statistics were conducted for HH compliance $(\%$, number of correct $\mathrm{HH}$ events per total number of observed $\mathrm{HH}$ events) and the TVC on the hand swabs. Binominal confidence intervals for $\mathrm{HH}$ compliance and glove usage were calculated using the hybrid Wilson/Brown method [49]. Contingency tables were calculated using the chi-square test. For multiple comparisons of TVC between groups (before patient contact, after patient contact, gloves, no gloves), ordinary one-way ANOVA was carried out. Significance was set at $p<0.05$. 


\section{Results}

\subsection{Hand Hygiene Compliance}

Overall, $1165 \mathrm{HH}$ evaluations were carried out: 810 of 1165 observations with the CleanHands application and 355 of 1165 with the WHO evaluation form. In 75 of 810 cases evaluated with the CleanHands application, $\mathrm{HH}$ could not be matched to any of the WHO five moments of $\mathrm{HH}$, i.e., $\mathrm{HH}$ was carried out without any indication. These cases were therefore classified as "non-coded" and were left out of the statistical analysis, leaving a total of 1090 observations (Table 1). Overall, $\mathrm{HH}$ compliance (95\% confidence interval) was $36.6 \%$ (33.8-39.5\%). The observed HH compliance with the WHO observation form (34.1\% $(29.3-39.2 \%))$ was not different to the one established with the CleanHands application $(37.8 \%(34.4-41.4 \%))($ Table 1$)$. Significant differences $(p=0.0035)$ were observed between different clinical areas (Table 1), with the highest compliance observed in the ICU $(44.0 \%$ $(37.9-50.3 \%))$ and the lowest in the pre-operation preparation area $(28.6 \%(22.9-35.0 \%))$. HH was significantly $(p<0.0001)$ more commonly performed after body fluid exposure $(55.8 \%(48.8-62.5 \%))$ and after patient contact $(51.6 \%(46.1-57.1 \%))$ than after touching the patient's surroundings (33.6\% (25.4-43.0\%)), before clean/aseptic/invasive procedures $(14.3 \%(10.4-19.6 \%))$ and before patient contact (23.5\% (18.6-29.1\%)) (Table 1). Differences within professional groups were not significant $(p=0.0879)$, but the group "others" $(29.5 \%$ $(23.4-36.5 \%))$ tended to perform lower than veterinarians (38.5\% (34.2-43.1\%)) and nurses $(37.6 \%(33.2-42.1 \%))$ (Table 1$)$.

Table 1. Number of hand hygiene observations and hand hygiene compliance within clinical areas, professional groups, and hand hygiene indications.

\begin{tabular}{ccc}
\hline & $\begin{array}{c}\text { Total Number and Percentages of Hand } \\
\text { Hygiene Observations }\end{array}$ & Hand Hygiene Compliance (95\% CI) \\
\hline Overall & 1090 & $36.6 \%(33.8-39.5 \%)$ \\
CleanHands application & $735(67.4 \%)$ & $37.8 \%(34.4-41.4 \%)$ \\
WHO evaluation form & $355(32.6 \%)$ & $34.1 \%(29.3-39.2 \%)$ \\
Area & $210(19.3 \%)$ & $28.6 \%(22.9-35.0 \%)$ \\
Pre-operation preparation area & $241(22.1 \%)$ & $44.0 \%(37.9-50.3 \%)$ \\
ICU & $194(17.8 \%)$ & $39.7 \%(33.1-46.7 \%)$ \\
Consultation & $215(19.7 \%)$ & $39.1 \%(32.8-45.7 \%)$ \\
Ward & $230(21.1 \%)$ & $31.3 \%(25.7-37.6 \%)$ \\
Examination area & & $38.5 \%(34.2-43.1 \%)$ \\
Professional group & $457(42.0 \%)$ & $37.6 \%(33.2-42.1 \%)$ \\
Veterinarian & $450(41.2 \%)$ & $29.5 \%(23.4-36.5 \%)$ \\
Nurse & $183(16.8 \%)$ & \\
Others & & $55.8 \%(48.8-62.5 \%)$ \\
Indication & $199(18.3 \%)$ & $51.6 \%(46.1-57.1 \%)$ \\
After patient contact & $314(28.8 \%)$ & $33.6 \%(25.4-43.0 \%)$ \\
After body fluid exposure risk & $107(9.8 \%)$ & $14.3 \%(10.4-19.6 \%)$ \\
Before clean/aseptic/invasive procedure & $223(20.4 \%)$ & $23.5 \%(18.6-29.1 \%)$ \\
Before patient contact & $247(22.7 \%)$ &
\end{tabular}

Abbreviations: ICU, intensive care unit; others, personnel not allocated to the categories, "veterinarian" or "nurse", such as students and technicians.

\subsection{Type of Hand Hygiene and Use of Gloves}

The WHO observation form revealed that alcohol-based hand rub was used in 68 of $121(56.2 \%(47.3-64.7 \%))$ observations where $\mathrm{HH}$ was performed $(\mathrm{n}=121)$, soap and water in 35 of $121(28.9 \%(21.6-37.6 \%))$ observations and both HH methods were applied in 18 of $121(14.9 \%(9.6-22.3 \%))$ observations. Gloves were worn in 78 of $355(22.0 \%(18.0-26.6 \%))$ observations. The use of gloves was indicated in 29 of these $78(37.2 \%(27.3-48.3 \%))$ observations. When using gloves, $\mathrm{HH}$ was carried out according to WHO recommendation in 18 of $78(23.1 \%(15.1-33.6 \%))$ observations. 


\subsection{Hand Swabs}

A total of 202 hand swabs (101 swabs before and 101 swabs after patient contact) were collected at 87 instances. Overall, mean TVC ( $95 \%$ confidence interval) before patient contact was lower $\left(0.52 \log \mathrm{CFU} / \mathrm{cm}^{2}[0.37-0.66]\right)$ than mean TVC after patient contact (1.02 $\left.\log \mathrm{CFU} / \mathrm{cm}^{2}(0.81-1.24)\right)$ (Figure 1). When not wearing gloves, mean TVC before patient contact was lower $\left(0.58 \mathrm{log} \mathrm{CFU} / \mathrm{cm}^{2}(0.41-0.75)\right)$ than after patient contact $\left(0.91 \log \mathrm{CFU} / \mathrm{cm}^{2}(0.67-1.15)\right)$. Similarly, mean TVC on gloves was lower before $\left(0.54 \log \mathrm{CFU} / \mathrm{cm}^{2}(0.17-0.90)\right)$ than after patient contact $\left(1.34 \log \mathrm{CFU} / \mathrm{cm}^{2}(0.79-1.88)\right)$. However, there was no difference in TVC before patient contact in staff wearing gloves versus not wearing gloves. Hand contamination was not significantly different $(p=0.1)$ between the areas. However, it was lowest in the ICU $\left(0.34 \log \mathrm{CFU} / \mathrm{cm}^{2}(0.14-0.54)\right)$ and highest in the patient examination area $\left(0.70 \log \mathrm{CFU} / \mathrm{cm}^{2}(0.45-0.95)\right)$. Additionally, there were no significant differences $(p=0.5774)$ in hand contamination between professional groups.

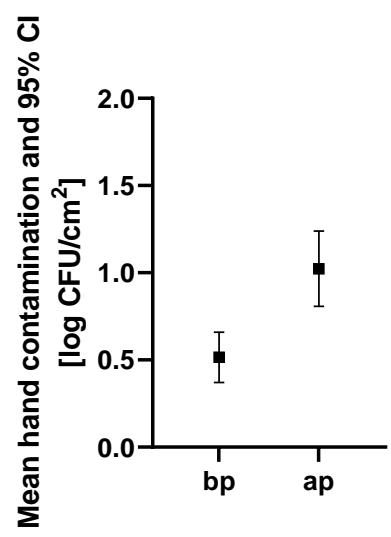

(a)

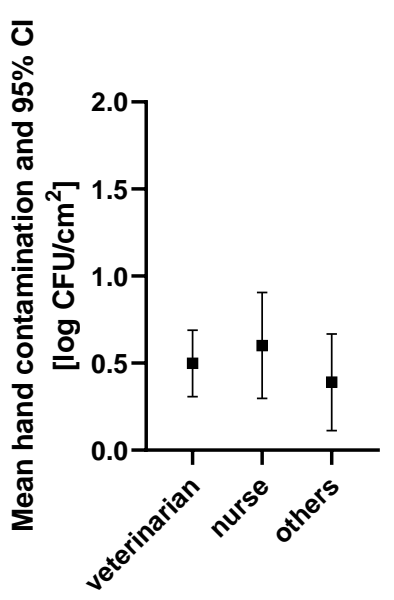

(c)

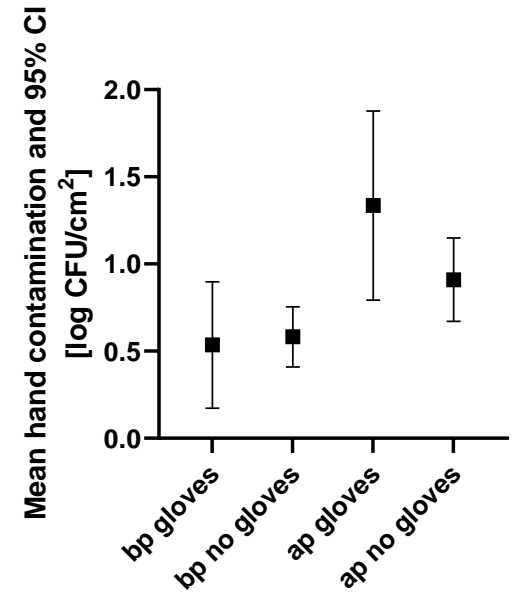

(b)

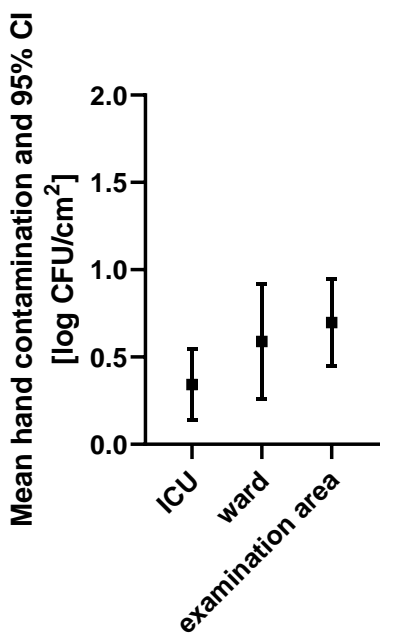

(d)

Figure 1. Hand contamination for different indications, professional groups, and clinical areas. Hand contamination (a) before and after patient contact, (b) before and after patient contact with and without gloves, (c) of different professional groups before patient contact, and (d) in different clinical areas before patient contact is indicated. Mean hand contamination and $95 \% \mathrm{CI}$ are indicated in $\log \mathrm{CFU} / \mathrm{cm}^{2}$. Abbreviations: bp, before patient contact; ap, after patient contact; others, personnel not allocated to the categories, "veterinarian" or "nurse", such as students and technicians; ICU, intensive care unit. 
MRSA was isolated from three hand swabs (1.5\% (0.4-4.3)). Two of these hand swabs were taken before patient contact and one after patient contact. All strains harbored the mecA gene. BZ_32_ap belonged to ST398 and spa type t011, BZ_38_bp to ST105 and spa type t002 and BZ_44_bp to ST 398 and spa type t011.

\section{Discussion}

Overall, $\mathrm{HH}$ compliance was poor (36.6\%) in the companion animal clinic evaluated in this study. These results mirror those recently found in seven companion animal clinics and practices in Switzerland where the average $\mathrm{HH}$ compliance was $32 \%$, ranging from $26 \%$ to $47 \%$ across the seven institutions. The results are also in line with those from previous veterinary studies where compliance ranged from $14 \%$ to $27 \%$ before and $14 \%$ to $42 \%$ after intervention [31-33]. However, those studies did not evaluate $\mathrm{HH}$ compliance in accordance with the WHO criteria; hence, comparison is limited. Our results highlight the need to foster $\mathrm{HH}$ intervention and training in companion animal medicine, given that $\mathrm{HH}$ is amongst the most important prevention measures for nosocomial infections $[25,50]$. The findings are in contrast to results from studies conducted in human healthcare, where $\mathrm{HH}$ compliance is generally higher, although a wide range exists among these studies [27].

Both evaluation tools used in this study obtained comparable results. The method using the WHO observation form was more time consuming due to the manual extraction and analysis of the data. However, it allowed the evaluation of additional criteria such as the type of $\mathrm{HH}$ performed and the use of gloves. The recently updated CleanHands application (Swissnoso, National Centre for Infection Prevention) additionally records the latter but was unavailable at the time of this study [51].

The higher HH compliance in the ICU in comparison to the other clinical areas, combined with a low hand contamination, was surprising. Intensive-care environments such as the ICU or the pre-operation preparation areas have been previously associated with lower compliances due to a high "activity index", i.e., number of observed HH opportunities per hour for each observation period [52] and higher-risk procedures [27,52,53]. Of note, the compliance levels observed in the ICU in this study were higher than those of a recent study conducted in seven companion animal clinics and practices across Switzerland [34]. In line with results from previous veterinary studies, $\mathrm{HH}$ compliance was highest after body fluid exposure and lowest before clean/aseptic/invasive procedures [31]. This implies that $\mathrm{HH}$ might mainly be used for self-protection instead of for patient protection [26].

Particular attention should be paid when using gloves, since wearing gloves is often misconceived as a substitute for $\mathrm{HH}[49,50,54,55]$. In this study, gloves were worn in $22.0 \%$ of $\mathrm{HH}$ indications, but the use of gloves was, according to WHO standards, indicated in only $37.2 \%$ of these observations. Additionally, $\mathrm{HH}$ when wearing gloves was only conducted in $23.1 \%$ of the observations. In one study, observed $\mathrm{HH}$ compliance after glove removal was 39\% [31]. Such low HH compliances are worrisome, as pre-existing defects, and damage during use and glove removal could pose potential hazards for hand contamination [53-55]. Therefore, wearing gloves is not considered a HH procedure by the WHO [26,30]. Of note, the TVC did not differ before patient contact in samples taken from gloved compared to ungloved hands of the healthcare workers. This underlines that wearing gloves does not automatically reduce the bacterial load on the hands and does not prevent transmission of pathogens. Moreover, gloves can potentially become contaminated when putting them on. Therefore, the $\mathrm{HH}$ indications apply regardless of the use of gloves [26,30].

Hands are regarded as the main risk factor for ARM transmission, and nosocomial pathogens have been reported on the hands of veterinary healthcare workers [56]. In this study, $1.5 \%$ of hand swabs tested positive for MRSA ST105 spa type t002 and ST398 spa type t011 harboring the mecA gene. MRSA ST105 is a frequently described ST, which has also been linked to an outbreak in a neonatal ICU [57]. The emergence of ST398 has been associated with infections in humans and animals, and has been isolated from a dog's wound and from the nose of a veterinary staff member of the same clinic [58]. In 
dogs, unlike in humans, Staphylococcus pseudintermedius, not Staphylococcus aureus, has been described as the more prevalent opportunistic pathogen [59]. A systematic review analyzing fifty-nine articles comprising 6840 hand cultures determined a pooled prevalence of $4.3 \%$ for MRSA on the hands of healthcare workers in human medicine [60]. In veterinary medicine, most studies analyze nasal carriage, and only few determined contamination of hands. Studies have reported drug-resistant Enterobacteriaceae on the hands of veterinary staff [56] and nosocomial pathogens have been isolated from the hands of healthcare workers [61]. One study found a MRSA and MRSP prevalence of $7 \%$ and $2 \%$, respectively, on the hands of veterinary staff [56], whereas another study found a prevalence of $0 \%$ for MRSA and 4.7\% for MRSP [62]. However, comparison between studies is challenging, as the sampling methods, i.e., cotton swab, direct contact, glove juice method, and study protocols vary.

The present study has some limitations. For one, the results of the $\mathrm{HH}$ observation could underly the Hawthorne effect, and thus be too optimistic, since direct observation could lead to a higher HH compliance $[63,64]$. However, according to WHO guidelines, direct observation is considered the gold standard when evaluating $\mathrm{HH}$ compliance [65]. Indeed, the WHO advises against hidden observation as it might be considered unethical to observe an individual's behavior without informed consent. Hidden observation could also lead to mistrust amongst the employees. Furthermore, a proportion of the observations in this study were conducted in the consultation rooms, where an introduction to the animal owner was unavoidable. The Hawthorne Effect is, however, assumed to be transient and most pronounced at the beginning of the observation period. Therefore, the observation sessions were conducted over a ten-week period. An inconspicuous positioning of the observer, as in this study, can also further minimize observer bias. A second limitation is that the present study was conducted in only one clinic and extrapolation of these results to other companion animal clinics may not be relevant in all comparisons. Our results on hand hygiene compliance were, however, comparable to those of a previous study performed in seven companion animal veterinary institutions in Switzerland and should thus be applicable and may be considered relevant in a broader context [34]. Thirdly, the number of hand swabs was limited, considering the number of hand-patient contacts that took place during a day.

\section{Conclusions}

The present study found a largely insufficient $\mathrm{HH}$ compliance in a large veterinary referral clinic for companion animals in Switzerland. HH was often neglected before patient contacts and before clean/aseptic/invasive procedures. The use of gloves was common, and gloves were frequently worn without indication. TVC before patient contact was similar when wearing gloves versus when not wearing gloves, confirming that wearing gloves cannot be considered a $\mathrm{HH}$ procedure; a finding in line with the WHO recommendations. The online tool and the WHO observation form gathered comparable results. Although the $\mathrm{WHO}$ observation form is more time-consuming, it allows for additional evaluation aspects. Future online applications should allow to differentiate the $\mathrm{HH}$ procedure performed (water and soap and alcohol-based hand rub) and include the use of gloves. There is a need for evidence-based recommendations on hygiene intervention in veterinary care settings and training on adequate $\mathrm{HH}$ should be fostered.

Supplementary Materials: The following are available online at https:/ / www.mdpi.com/article/10 $.3390 /$ vetsci8110260/s1. Table S1: Indications for hand hygiene according to the WHO and examples.

Author Contributions: Conceptualization, R.S., B.W. and K.S.; methodology, R.S., B.W., K.S. and A.B.E.Z.; validation, R.S., B.W. and K.S.; formal analysis, R.S., B.W., K.S. and A.B.E.Z.; investigation, K.S. and A.B.E.Z.; resources, R.S. and B.W.; data curation, R.S., B.W., K.S. and A.B.E.Z.; writing-original draft preparation, K.S.; writing—review \& editing, R.S., B.W., K.S. and A.B.E.Z.; visualization, K.S.; supervision, R.S., B.W. and K.S.; project administration, R.S., B.W. and K.S.; funding acquisition, not applicable. All authors have read and agreed to the published version of the manuscript. 
Funding: This research was funded by the University of Zurich.

Institutional Review Board Statement: In accordance with local legislation, ethical approval was sought from the Swiss Ethics Committees on research involving humans (2019-00768).

Informed Consent Statement: Informed consent was obtained from all subjects involved in the study.

Data Availability Statement: The datasets used and analyzed during the current study are available from the corresponding author upon reasonable request.

Acknowledgments: We thank the staff of the veterinary clinic for their participation in this study. This study was topic of the Master's thesis of Anna Barbara Emilia Zimmermann and part of the Ph.D. project of Kira Schmitt.

Conflicts of Interest: The authors declare no conflict of interest.

\section{References}

1. Grönthal, T.; Moodley, A.; Nykäsenoja, S.; Junnila, J.; Guardabassi, L.; Thomson, K.; Rantala, M. Large outbreak caused by methicillin-resistant Staphylococcus pseudintermedius ST71 in a Finnish veterinary teaching hospital—From outbreak control to outbreak prevention. PLOS ONE 2014, 9, e110084.

2. Grönlund Andersson, U.; Wallensten, A.; Hæggman, S.; Greko, C.; Hedin, G.; Hökeberg, I.; Lindström, F.; Olsson-Liljequist, B.; Smedjegård, J.; Söderblom, T.; et al. Outbreaks of methicillin-resistant Staphylococcus aureus among staff and dogs in Swedish small animal hospitals. Scand. J. Infect. Dis. 2014, 46, 310-314. [CrossRef]

3. Leonard, F.C.; Abbott, Y.; Rossney, A.; Quinn, P.J.; O'Mahony, R.; Markey, B.K. Methicillin-resistant Staphylococcus aureus isolated from a veterinary surgeon and five dogs in one practice. Vet. Rec. 2006, 158, 155-159. [CrossRef] [PubMed]

4. Rojas, I.; Barquero-Calvo, E.; van Balen, J.C.; Rojas, N.; Muñoz-Vargas, L.; Hoet, A.E. High prevalence of multidrug-resistant community-acquired methicillin-resistant Staphylococcus aureus at the largest veterinary teaching hospital in Costa Rica. VectorBorne Zoonotic Dis. 2017, 17, 645-653. [CrossRef]

5. $\quad$ Singleton, D.A.; Sánchez-Vizcaíno, F.; Dawson, S.; Jones, P.H.; Noble, P.J.M.; Pinchbeck, G.L.; Williams, N.J.; Radford, A.D. Patterns of antimicrobial agent prescription in a sentinel population of canine and feline veterinary practices in the United Kingdom. Vet. J. 2017, 224, 18-24. [CrossRef]

6. Buckland, E.L.; O’Neill, D.; Summers, J.; Mateus, A.; Church, D.; Redmond, L.; Brodbelt, D. Characterisation of antimicrobial usage in cats and dogs attending UK primary care companion animal veterinary practices. Vet. Rec. 2016, 179, 489. [CrossRef]

7. Smith, A.; Wayne, A.S.; Fellman, C.L.; Rosenbaum, M.H. Usage patterns of carbapenem antimicrobials in dogs and cats at a veterinary tertiary care hospital. J. Vet. Intern. Med. 2019, 33, 1677-1685. [CrossRef] [PubMed]

8. Hubbuch, A.; Schmitt, K.; Lehner, C.; Hartnack, S.; Schuller, S.; Schüpbach-Regula, G.; Mevissen, M.; Peter, R.; Müntener, C.; Naegeli, H.; et al. Antimicrobial prescriptions in cats in Switzerland before and after the introduction of an online antimicrobial stewardship tool. BMC Vet. Res. 2020, 16, 229. [CrossRef] [PubMed]

9. Mateus, A.; Brodbelt, D.C.; Barber, N.; Stärk, K.D.C. Antimicrobial usage in dogs and cats in first opinion veterinary practices in the UK. J. Small Anim. Pract. 2011, 52, 515-521. [CrossRef]

10. Radford, A.D.; Noble, P.J.; Coyne, K.P.; Gaskell, R.M.; Jones, P.H.; Bryan, J.G.E.; Setzkorn, C.; Tierney, A.; Dawson, S. Antibacterial prescribing patterns in small animal veterinary practice identified via SAVSNET: The small animal veterinary surveillance network. Vet. Rec. 2011, 169, 310. [CrossRef]

11. Van Cleven, A.; Sarrazin, S.; de Rooster, H.; Paepe, D.; Van der Meeren, S.; Dewulf, J. Antimicrobial prescribing behaviour in dogs and cats by Belgian veterinarians. Vet. Rec. 2018, 182, 324. [CrossRef]

12. De Briyne, N.; Atkinson, J.; Borriello, S.P.; Pokludová, L. Antibiotics used most commonly to treat animals in Europe. Vet. Rec. 2014, 175, 325. [CrossRef]

13. Sarrazin, S.; Vandael, F.; Van Cleven, A.; De Graef, E.; De Rooster, H.; Dewulf, J.; Be Bstract, S.S. The impact of antimicrobial use guidelines on prescription habits in fourteen Flemish small animal practices. Vlaams Diergeneeskd. Tijdschr. 2017, 86, 173-182. [CrossRef]

14. Murphy, C.P.; Reid-Smith, R.J.; Boerlin, P.; Weese, J.S.; Prescott, J.F.; Janecko, N.; McEwen, S.A. Out-patient antimicrobial drug use in dogs and cats for new disease events from community companion animal practices in Ontario. Can. Vet. J. 2012, 53, $291-298$.

15. Hardefeldt, L.Y.; Selinger, J.; Stevenson, M.A.; Gilkerson, J.R.; Crabb, H.; Billman-Jacobe, H.; Thursky, K.; Bailey, K.E.; Awad, M.; Browning, G.F. Population wide assessment of antimicrobial use in dogs and cats using a novel data source-A cohort study using pet insurance data. Vet. Microbiol. 2018, 225, 34-39. [CrossRef] undefined

16. Schmitt, K.; Lehner, C.; Schuller, S.; Schüpbach-Regula, G.; Mevissen, M.; Peter, R.; Müntener, C.R.; Naegeli, H.; Willi, B. Antimicrobial use for selected diseases in cats in Switzerland. BMC Vet. Res. 2019, 15, 94. [CrossRef] 
17. Schmidt, J.S.; Kuster, S.P.; Nigg, A.; Dazio, V.; Brilhante, M.; Rohrbach, H.; Bernasconi, O.J.; Büdel, T.; Campos-Madueno, E.I.; Gobeli Brawand, S.; et al. Poor infection prevention and control standards are associated with environmental contamination with carbapenemase-producing Enterobacterales and other multidrug-resistant bacteria in Swiss companion animal clinics. Antimicrob. Resist. Infect. Control. 2020, 9, 93. [CrossRef] [PubMed]

18. Zogg, A.L.; Zurfluh, K.; Schmitt, S.; Nüesch-Inderbinen, M.; Stephan, R. Antimicrobial resistance, multilocus sequence types and virulence profiles of ESBL producing and non-ESBL producing uropathogenic Escherichia coli isolated from cats and dogs in Switzerland. Vet. Microbiol. 2018, 216, 79-84. [CrossRef]

19. Nüesch-Inderbinen, M.T.; Baschera, M.; Zurfluh, K.; Hächler, H.; Nüesch, H.; Stephan, R. Clonal diversity, virulence potential and antimicrobial resistance of Escherichia coli causing community acquired urinary tract infection in Switzerland. Front. Microbiol. 2017, 8, 2334. [CrossRef] [PubMed]

20. Van den Bunt, G.; Fluit, A.C.; Spaninks, M.P.; Timmerman, A.J.; Geurts, Y.; Kant, A.; Scharringa, J.; Mevius, D.; Wagenaar, J.A.; Bonten, M.J.M.; et al. Faecal carriage, risk factors, acquisition and persistence of ESBL-producing Enterobacteriaceae in dogs and cats and co-carriage with humans belonging to the same household. J. Antimicrob. Chemother. 2020, 75, 342-350. [CrossRef]

21. Schmitt, K.; Kuster, S.P.; Zurfluh, K.; Jud, R.S.; Sykes, J.E.; Stephan, R.; Willi, B. Transmission Chains of Extended-Spectrum Beta-Lactamase-Producing Enterobacteriaceae at the Companion Animal Veterinary Clinic-Household Interface. Antibiotics 2021, 10, 171. [CrossRef]

22. Pittet, D.; Allegranzi, B.; Boyce, J. The World Health Organization Guidelines on Hand Hygiene in Health Care and Their Consensus Recommendations. Infect. Control. Hosp. Epidemiol. 2009, 30, 611-622. [CrossRef]

23. Boyce, J.M. MRSA patients: Proven methods to treat colonization and infection. J. Hosp. Infect. 2001, 48, S9-S14. [CrossRef]

24. Marimuthu, K.; Pittet, D.; Harbarth, S. The effect of improved hand hygiene on nosocomial MRSA control. Antimicrob. Resist. Infect. Control. 2014, 3, 34. [CrossRef]

25. Haley, R.W.; Culver, D.H.; White, J.W.; Morgan, W.M.; Emori, T.G.; Munn, V.P.; Hooton, T.M. The efficacy of infection surveillance and control programs in preventing nosocomial infections in US hospitals. Am. J. Epidemiol. 1985, 121, 182-205. [CrossRef] [PubMed]

26. Sax, H.; Allegranzi, B.; Chraïti, M.-N.; Boyce, J.; Larson, E.; Pittet, D. The World Health Organization hand hygiene observation method. Am. J. Infect. Control. 2009, 37, 827-834. [CrossRef]

27. Alshehari, A.A.; Park, S.; Rashid, H. Strategies to improve hand hygiene compliance among healthcare workers in adult intensive care units: A mini systematic review. J. Hosp. Infect. 2018, 100, 152-158. [CrossRef] [PubMed]

28. World Health Organisation WHO I Five Moments for Hand Hygiene. Available online: https://www.who.int/gpsc/tools/Five_ moments/en/ (accessed on 22 June 2021).

29. Gerberding, J.L.; Fleming, M.W.D.; Snider, D.E.; Thacker, S.B.; Ward, J.W.; Hewitt, S.M.; Douglas, W.R.W.; Weatherwax, M.J.; Beverly, J.H.; Holland, M.A.; et al. Morbidity and Mortality Weekly Report Guideline for Hand Hygiene in Health-Care Settings Recommendations of the Healthcare Infection Control. Practices Advisory Committee and the HICPAC/SHEA/APIC/IDSA Hand Hygiene Task Force Centers for Disease Control and Prevention; SHEA/APIC/IDSA Hand Hygiene Task Force: Atlanta, GA, USA, 2002; Volume 51.

30. WHO. WHO Guidelines on Hand Hygiene in Health Care First Global Patient Safety Challenge Clean Care Is Safer Care; WHO: Geneva, Switzerland, 2009; ISBN 9789241597906.

31. Anderson, M.E.; Sargeant, J.M.; Weese, J. Video observation of hand hygiene practices during routine companion animal appointments and the effect of a poster intervention on hand hygiene compliance. BMC Vet. Res. 2014, 10, 106. [CrossRef] [PubMed]

32. Smith, J.R.; Packman, Z.R.; Hofmeister, E.H. Multimodal evaluation of the effectiveness of a hand hygiene educational campaign at a small animal veterinary teaching hospital. J. Am. Vet. Med. Assoc. 2013, 243, 1042-1048. [CrossRef]

33. Shea, A.; Shaw, S. Evaluation of an educational campaign to increase hand hygiene at a small animal veterinary teaching hospital. J. Am. Vet. Med. Assoc. 2012, 240, 61-64. [CrossRef] [PubMed]

34. Schmidt, J.S.; Hartnack, S.; Schuller, S.; Kuster, S.P.; Willi, B. Hand hygiene compliance in companion animal clinics and practices in Switzerland: An observational study. Vet. Rec. 2021, e307. [CrossRef]

35. Monitoring Tools. Available online: https://www.who.int/teams/integrated-health-services/infection-prevention-control/ hand-hygiene/monitoring-tools (accessed on 14 June 2021).

36. Schöbi, B.; Kuhn, R.; Kahlert, C.S.M. CleanHands: Handbuch; National Centre for Infection Prevention: Bern, Switzerland, 2015. Available online: https://www.swissnoso.ch/fileadmin/module/cleanhands/Dokumente/cleanhands_manual_D.pdf (accessed on 21 June 2021).

37. World Health Organization; WHO Patient Safety. Hand Hygiene Technical Reference Manual: To Be Used by Health-Care Workers, Trainers and Observers of Hand Hygiene Practices; World Health Organization: Geneva, Switzerland, $2009 ;$ ISBN 9789241598606.

38. Verbraecken, J.; Van De Heyning, P.; De Backer, W.; Van Gaal, L. Body surface area in normal-weight, overweight, and obese adults. A comparison study. Metabolism 2006, 55, 515-524. [CrossRef]

39. Rhodes, J.; Clay, C.; Phillips, M. The surface area of the hand and the palm for estimating percentage of total body surface area: Results of a meta-analysis. Br. J. Dermatol. 2013, 169, 76-84. [CrossRef] [PubMed] 
40. Zogg, A.L.; Simmen, S.; Zurfluh, K.; Stephan, R.; Schmitt, S.N.; Nüesch-Inderbinen, M. High prevalence of extended-spectrum $\beta$-lactamase producing Enterobacteriaceae among clinical isolates from cats and dogs admitted to a veterinary hospital in Switzerland. Front. Vet. Sci. 2018, 5, 62. [CrossRef] [PubMed]

41. Geser, N.; Stephan, R.; Korczak, B.M.; Beutin, L.; Hächler, H. Molecular identification of extended-spectrum- $\beta$-lactamase genes from Enterobacteriaceae isolated from healthy human carriers in Switzerland. Antimicrob. Agents Chemother. 2012, 56, 1609-1612. [CrossRef] [PubMed]

42. Woodford, N.; Fagan, E.J.; Ellington, M.J. Multiplex PCR for rapid detection of genes encoding CTX-M extended-spectrum $\beta$-lactamases. J. Antimicrob. Chemother. 2006, 57, 154-155. [CrossRef] [PubMed]

43. Zurfluh, K.; Nüesch-Inderbinen, M.; Morach, M.; Zihler Berner, A.; Hächler, H.; Stephan, R. Extended-spectrum- $\beta$-lactamaseproducing Enterobacteriaceae isolated from vegetables imported from the Dominican Republic, India, Thailand, and Vietnam. Appl. Environ. Microbiol. 2015, 81, 3115-3120. [CrossRef]

44. Poirel, L.; Walsh, T.R.; Cuvillier, V.; Nordmann, P. Multiplex PCR for detection of acquired carbapenemase genes. Diagn. Microbiol. Infect. Dis. 2011, 70, 119-123. [CrossRef]

45. Ellington, M.J.; Kistler, J.; Livermore, D.M.; Woodford, N. Multiplex PCR for rapid detection of genes encoding acquired metallo- $\beta$-lactamases. J. Antimicrob. Chemother. 2007, 59, 321-322. [CrossRef]

46. Dutka-Malen, S.; Evers, S.; Courvalin, P. Detection of glycopeptide resistance genotypes and identification to the species level of clinically relevant enterococci by PCR. J. Clin. Microbiol. 1995, 33, 24-27. [CrossRef]

47. Mehrotra, M.; Wang, G.; Johnson, W.M. Multiplex PCR for detection of genes for Staphylococcus aureus enterotoxins, exfoliative toxins, toxic shock syndrome toxin 1, and methicillin resistance. J. Clin. Microbiol. 2000, 38, 1032-1035. [CrossRef] [PubMed]

48. Stegger, M.; Andersen, P.S.; Kearns, A.; Pichon, B.; Holmes, M.A.; Edwards, G.; Laurent, F.; Teale, C.; Skov, R.; Larsen, A.R. Rapid detection, differentiation and typing of methicillin-resistant Staphylococcus aureus harbouring either mecA or the new mecA homologue mecALGA251. Clin. Microbiol. Infect. 2012, 18, 395-400. [CrossRef] [PubMed]

49. Brown, L.D.; Cai, T.T.; DasGupta, A. Interval Estimation for a Binomial Proportion. Stat. Sci. 2001, 16, 101-133. [CrossRef]

50. Pittet, D. Improving compliance with hand hygiene in hospitals. Infect. Control Hosp. Epidemiol. 2000, 21, 381-386. [CrossRef]

51. Kuhn, R.; Frischknecht, M.; Kahlert, C.; Schlegel, M. CCM-CleanHands: Handbuch. 2021. Available online: https://www. swissnoso.ch/module/ccm-cleanhands/material/handbuch (accessed on 23 June 2021).

52. Pittet, D.; Mourouga, P.; Perneger, T.V. Compliance with Handwashing in a Teaching Hospital. Ann. Intern. Med. 1999, $130,126$. [CrossRef]

53. Olsen, R.J. Examination Gloves as Barriers to Hand Contamination in Clinical Practice. JAMA J. Am. Med. Assoc. 1993, 270, 350. [CrossRef]

54. Scheftel, J.M.; Elchos, B.L.; Cherry, B.; DeBess, E.E.; Hopkins, S.G.; Levine, J.F.; Williams, C.J.; Bell, M.R.; Dvorak, G.D.; Funk, R.H.; et al. Compendium of Veterinary Standard Precautions for Zoonotic Disease Prevention in Veterinary Personnel: National Association of State Public Health Veterinarians Veterinary Infection Control Committee 2010. J. Am. Vet. Med. Assoc. 2010, 237, 1403-1422. [CrossRef]

55. Boyce, J.M.; Pittet, D. Guideline for Hand Hygiene in Health-Care Settings: Recommendations of the Healthcare Infection Control Practices Advisory Committee and the HICPAC/SHEA/APIC/IDSA Hand Hygiene Task Force. Infect. Control. Hosp. Epidemiol. 2002, 23, S3-S40. [CrossRef] [PubMed]

56. Espadale, E.; Pinchbeck, G.; Williams, N.J.; Timofte, D.; McIntyre, K.M.; Schmidt, V.M. Are the hands of veterinary staff a reservoir for antimicrobial-resistant bacteria? A randomized study to evaluate two hand hygiene rubs in a veterinary hospital. Microb. Drug Resist. 2018, 24, 1607-1616. [CrossRef]

57. Sullivan, M.; Altman, D.; Webster, E.; Lewis, M.; Khan, Z.; Beckford, C.; Ciferri, B.; Deikus, G.; Rendo, A.; Samaroo, F.; et al. Continuous Surveillance by Whole-Genome Sequencing to Identify and Manage Methicillin-Resistant Staphylococcus aureus Outbreaks. Open Forum Infect. Dis. 2016, 3 (Suppl. 1), 942. [CrossRef]

58. Witte, W.; Strommenger, B.; Stanek, C.; Cuny, C. Methicillin-resistant Staphylococcus aureus ST398 in humans and animals, central Europe. Emerg. Infect. Dis. 2007, 13, 255-258. [CrossRef]

59. Perreten, V.; Kadlec, K.; Schwarz, S.; Gronlund Andersson, U.; Finn, M.; Greko, C.; Moodley, A.; Kania, S.A.; Frank, L.A.; Bemis, D.A.; et al. Clonal spread of methicillin-resistant Staphylococcus pseudintermedius in Europe and North America: An international multicentre study. J. Antimicrob. Chemother. 2010, 65, 1145-1154. [CrossRef]

60. Montoya, A.; Schildhouse, R.; Goyal, A.; Mann, J.D.; Snyder, A.; Chopra, V.; Mody, L. How often are health care personnel hands colonized with multidrug- resistant organisms? A systematic review and meta-analysis. Am. J. Infect. Control. 2019, 47, 693-703. [CrossRef]

61. Kampf, G.; Löffler, H.; Gastmeier, P. Hand hygiene for the prevention of nosocomial infections. Dtsch. Aerzteblatt Online 2009, 106, 649-655. [CrossRef] [PubMed]

62. Feßler, A.T.; Schuenemann, R.; Kadlec, K.; Hensel, V.; Brombach, J.; Murugaiyan, J.; Oechtering, G.; Burgener, I.A.; Schwarz, S. Methicillin-resistant Staphylococcus aureus (MRSA) and methicillin-resistant Staphylococcus pseudintermedius (MRSP) among employees and in the environment of a small animal hospital. Vet. Microbiol. 2018, 221, 153-158. [CrossRef] [PubMed]

63. Hagel, S.; Reischke, J.; Kesselmeier, M.; Winning, J.; Gastmeier, P.; Brunkhorst, F.M.; Scherag, A.; Pletz, M.W. Quantifying the Hawthorne effect in hand hygiene compliance through comparing direct observation with automated hand hygiene monitoring. Infect. Control. Hosp. Epidemiol. 2015, 36, 957-962. [CrossRef] [PubMed] 
64. Eckmanns, T.; Bessert, J.; Behnke, M.; Gastmeier, P.; Rüden, H. Compliance with antiseptic hand rub use in intensive care units the Hawthorne effect. Infect. Control. Hosp. Epidemiol. 2006, 27, 931-934. [CrossRef]

65. World Health Organization. WHO Guidelines on Hand Hygiene in Health Care: A Summary; WHO: Geneva, Switzerland, 2009. 